\title{
Corredores Verdes Urbanos como Elementos da Infraestrutura Sustentável
}

\author{
Grenways as Elements of Sustainable Infrastructure
}

Vias verdes urbanos como elementos de infraestructura sostenible

Mirian Carasek Professora Mestre Arquiteta, UPF, Brasil. miriancarasek@upf.br

Juan José Mascaró Professor Doutor Arquiteto, USP, Brasil juan@upf.br

Alex Garcia Borges Graduando em Arquitetura, UPF, Brasil alexgarciaborges4@hotmail.com 


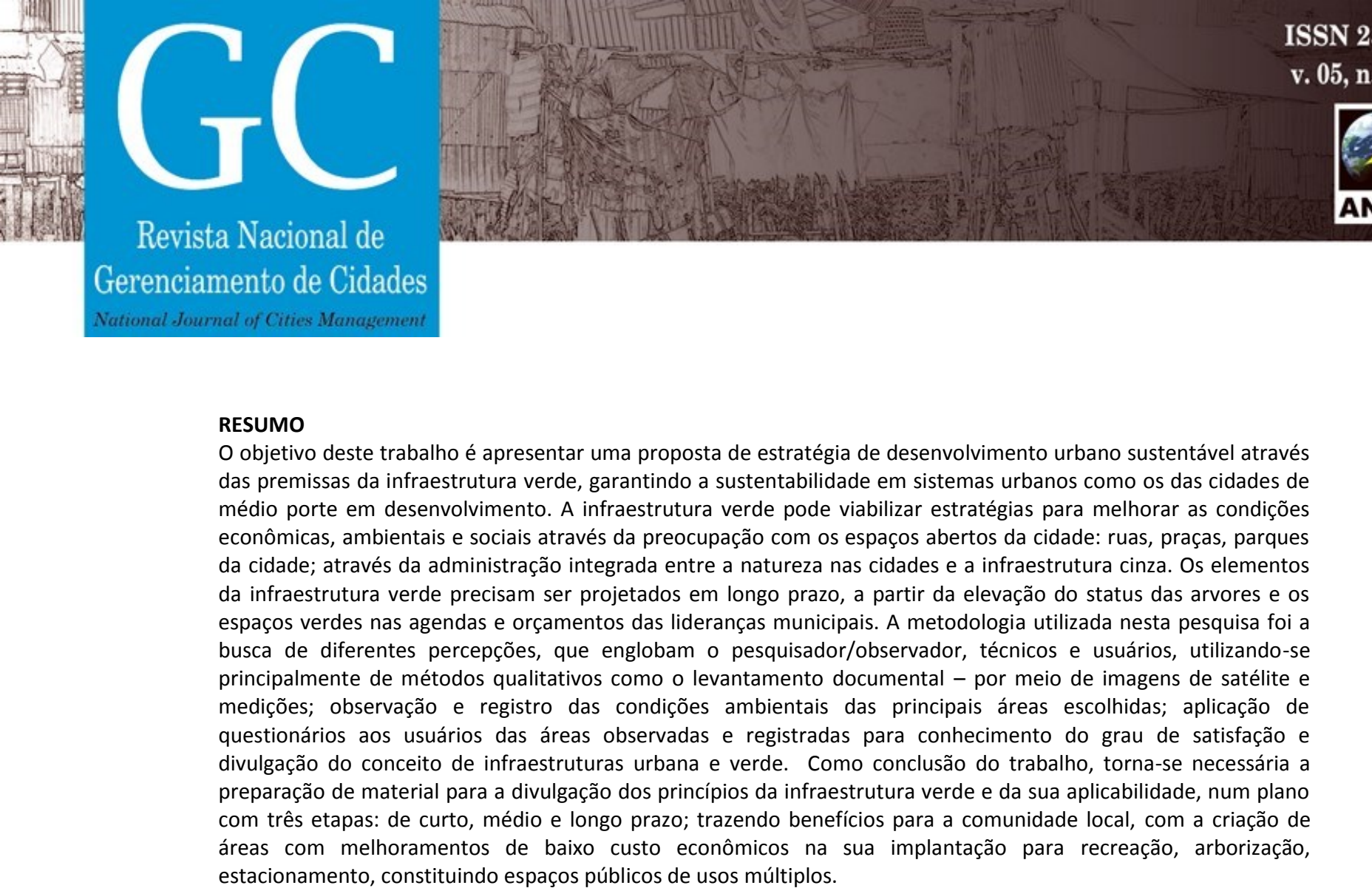

\title{
RESUMO
} médio porte em desenvolvimento. A infraestrutura verde pode viabilizar estratégias para melhorar as condições econômicas, ambientais e sociais através da preocupação com os espaços abertos da cidade: ruas, praças, parques da cidade; através da administração integrada entre a natureza nas cidades e a infraestrutura cinza. Os elementos medições; observação e registro das condições ambientais das principais áreas escolhidas; aplicação de questionários aos usuários das áreas observadas e registradas para conhecimento do grau de satisfação e divulgação do conceito de infraestruturas urbana e verde. Como conclusão do trabalho, torna-se necessária a preparação de material para a divulgação dos princípios da infraestrutura verde e da sua aplicabilidade, num plano áreas com melhoramentos de baixo custo econômicos na sua implantação para recreação, arborização, estacionamento, constituindo espaços públicos de usos múltiplos.

PALAVRAS-CHAVE: Infraestrutura urbana. Desenvolvimento sustentável. Corredores verdes urbanos

\begin{abstract}
The purpose of this work is to present a proposal for sustainable urban development through the premises of green infrastructure, guaranteeing the sustainability in urban systems, such as, those of the midsize cities in development. The green infrastructure can enable strategies to improve economic, environmental and social conditions that concern for the open spaces like for example streets, squares, city parks; considering integrated management between nature in cities and gray infrastructure. The elements of the green infrastructure need to be designed considering the long term, and the status of the trees in the green spaces in the agendas and budgets of the municipal leaderships. The methodology used in this research was the search for different perceptions, which include the researcher / observer, technicians and users, using mainly qualitative methods such as the documentary survey - through satellite images and measurements; Observation and recording of the environmental conditions of the main areas chosen; Application of questionnaires to the users of the areas observed and registered to know the degree of satisfaction and dissemination of the concept of urban and green infrastructures. As a conclusion of the work, it is necessary to prepare material for studying and disseminating the principles of green infrastructure and its applicability in a three-step plan: short, medium and long term; Which would most definitely bring benefits to the local communities with the creation of areas with low cost economic improvements in their implantation for recreation, afforestation, parking, constituting public spaces of multiple uses.
\end{abstract}

KEYWORDS: Urban Infrastructure. Sustainable development. Greenways.

\section{RESUMEN}

El objetivo de este trabajo es presentar una propuesta de estrategia de desarrollo urbano sostenible las ciudades de tamaño medio en el desarrollo a través de las instalaciones de infraestructura verde, garantizar la sostenibilidad de los sistemas urbanos. La infraestructura verde puede permitir estrategias para mejorar las condiciones económicas, medioambientales y sociales a través de la preocupación por los espacios abiertos de la ciudad: calles, plazas, parques; a través de la gestión La infraestructura verde puede permitir estrategias para mejorar las condiciones económicas, medioambientales y sociales. Los elementos de la infraestructura verde deben ser diseñados en el largo plazo, a partir de la elevación del estado de los árboles y los espacios verdes en las agendas y presupuestos de los líderes municipales. La metodología utilizada en esta investigación fue la búsqueda de percepciones diferentes, que incluyen el investigador / observador, técnicos y usuarios, utilizando principalmente métodos cualitativos como 


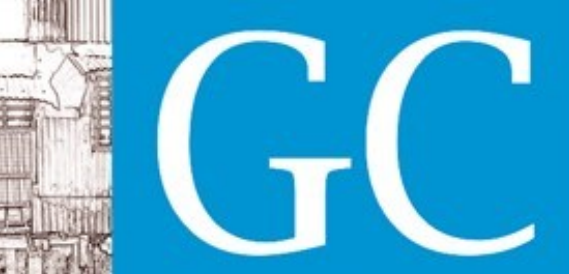

\section{Revista Nacional de}

\section{Gerenciamento de Cidades}

National Journal of Cities Management

la encuesta documental - a través de imágenes de satélite y mediciones; la observación y registro de las condiciones ambientales de las principales áreas elegidas; cuestionarios a los usuarios de las zonas observadas y registradas por el conocimiento del grado de satisfacción y la difusión del concepto de la infraestructura urbana y verde. Como conclusión del trabajo, es necesario preparar la poblacion y los lideres municipales para la difusión de los principios de la infraestructura verde y su aplicabilidad en un plan de tres fases: a corto, mediano y largo plazo; trayendo beneficios a la comunidad local, con la creación de áreas con mejoras económicas de bajo coste en su aplicación para la recreación, árboles, aparcamiento, proporcionando espacios públicos para usos múltiples.

PALABRAS CLAVE: Infraestructura urbana. Desenvolvimiento sustentable. Vías verdes urbanas 



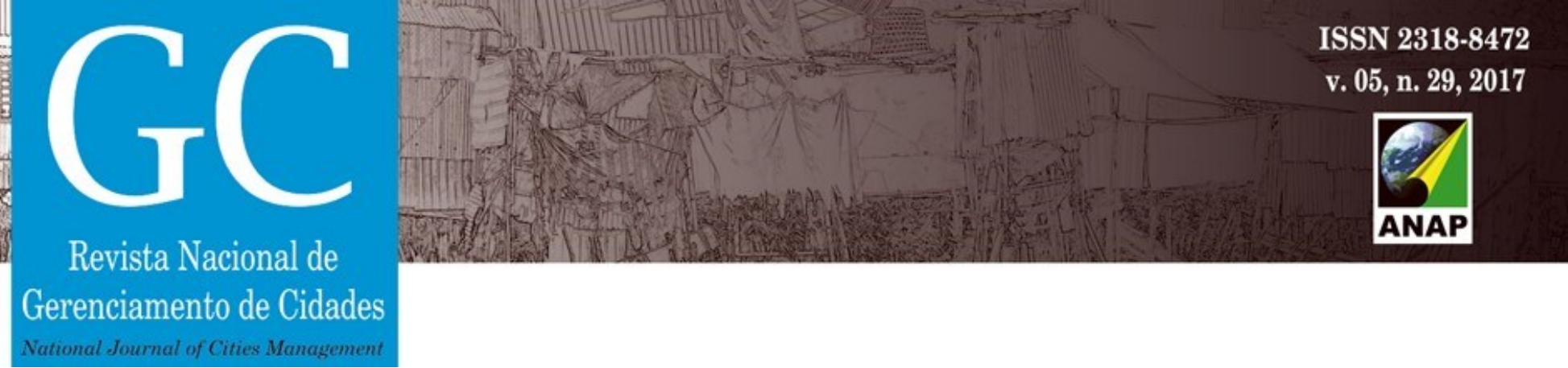

Assim, a área central não sofre um processo de degradação perante a competição das novas funções localizadas em outras da nova centralidade. A necessidade de complementar a estruturação radial com a integração e promoção do desenvolvimento das áreas periféricas, assim como a possibilidade de ligar diferentes centros de interesse urbano como equipamentos, áreas de lazer, parques e praças propõem a ideia de um sistema complementar da atual rede principal viária urbana que permita a estruturação dos fragmentos urbanos, hoje, sem conexões.

A infraestrutura verde pode ser considerada como uma das respostas adequadas para essa necessária estruturação dos fragmentos urbanos conectando áreas de interesse através de corredores tratados ambiental e culturalmente, com o mínimo de investimento e o máximo de apoio da população usuária; estruturação que propõe a inserção de equipamentos, complementação da infraestrutura existente, o melhoramento da rede viária e das calçadas e a valoração ambiental e do patrimônio arquitetônico e urbano. Estes últimos são elementos referenciais que outorgam identidade e iniciam um processo de integração ao sistema urbano promovendo o desenvolvimento das áreas de influência.

O objetivo da recuperação ambiental da cidade considera do ponto de vista do desenvolvimento urbano, um conceito integrado tendente a otimizar as condições ecológicas a partir das intervenções sobre o espaço físico. Uma das ações diretas a ser implementada com máxima intensidade seria a de arborização, atualização e manutenção das áreas verdes existentes, assim como a criação de novos espaços livres vegetados, orientados, de modo a gerar um sistema que integre uma nova trama verde sobre outras existentes, insuficientes e sem conexão atualmente.

Levantamento, observação e registro dos trechos escolhidos para o estudo permitiu conhecer suas características geométricas assim como seus subsistemas existentes. Comentamos o primeiro trecho estudado. 


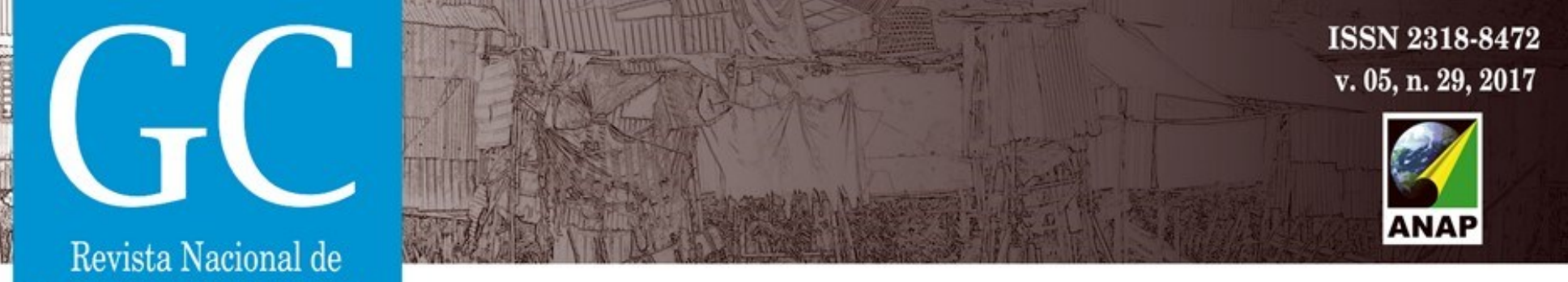

Gerenciamento de Cidades

A leitura do entorno escolhido: Este fragmento da área central da cidade encontra-se inserido na malha urbana fortemente consolidada. Realizando uma leitura dos aspectos perceptuais deste fragmento se observa que:

- o construído domina amplamente sobre o vazio, o que determina uma leitura com características de centro urbano;

- $\quad$ sua acessibilidade não é complexa embora as numerosas opções de vias que se apresentam é tanto de pedestres como veicular;

- $\quad$ pontualmente, produz-se o efeito de figura e fundo nos volumes constituídos pelos elementos arbóreos e o volume construído;

- a textura visual está dada pelo ritmo das janelas e sua escala dentro do volume edificado;

- $\quad$ outros componentes do mobiliário urbano, que contribuem para sua legibilidade, o que dá escala ao corredor e às vias conectoras são as sinaleiras. Os postes de energia elétrica, telefone, TV e iluminação pública atuam em escalas diferentes, com nenhum significado cromático ou volumétrico, mimetizando-se com a paisagem;

- a sinalização é discreta com acento nos cartazes destinado ao trânsito de veículos;

- $\quad$ nos recursos publicitários, aparece dominante a imagem corporativa;

- $\quad$ na leitura noturna, a cor dominante é a da iluminação pública seguida pontualmente pelos cartazes de propaganda comercial;

- nas horas da manhã e da tarde, dominam as atividades comerciais, com maior afluência de público, destacado pelo congestionamento de veículos e a saturação das áreas de estacionamento;

- $\quad$ nos feriados e finais de semana, percebe-se menor afluência de público, mas não abandono dos espaços.

Na pesquisa a praça é considerada e analisada como lugar de encontro e sociabilidade urbana. A praça: conjunto semântico que retrotrai ao espaço arcaico, à infância, aos amores, aos festejos do povo, à vivência de cidadania. Estudar a praça é nossa missão. Revitalizar praças é nossa utopia.

As praças escolhidas para analisar sua possível inclusão na proposta de infraestrutura verde para Passo Fundo são a Praça Tamandaré e a Praça Antônio Xavier. A Figura 7 mostra suas localizações na parte da malha urbana em estudo. A abordagem e análise são dos aspectos geométricos e vivenciais. 


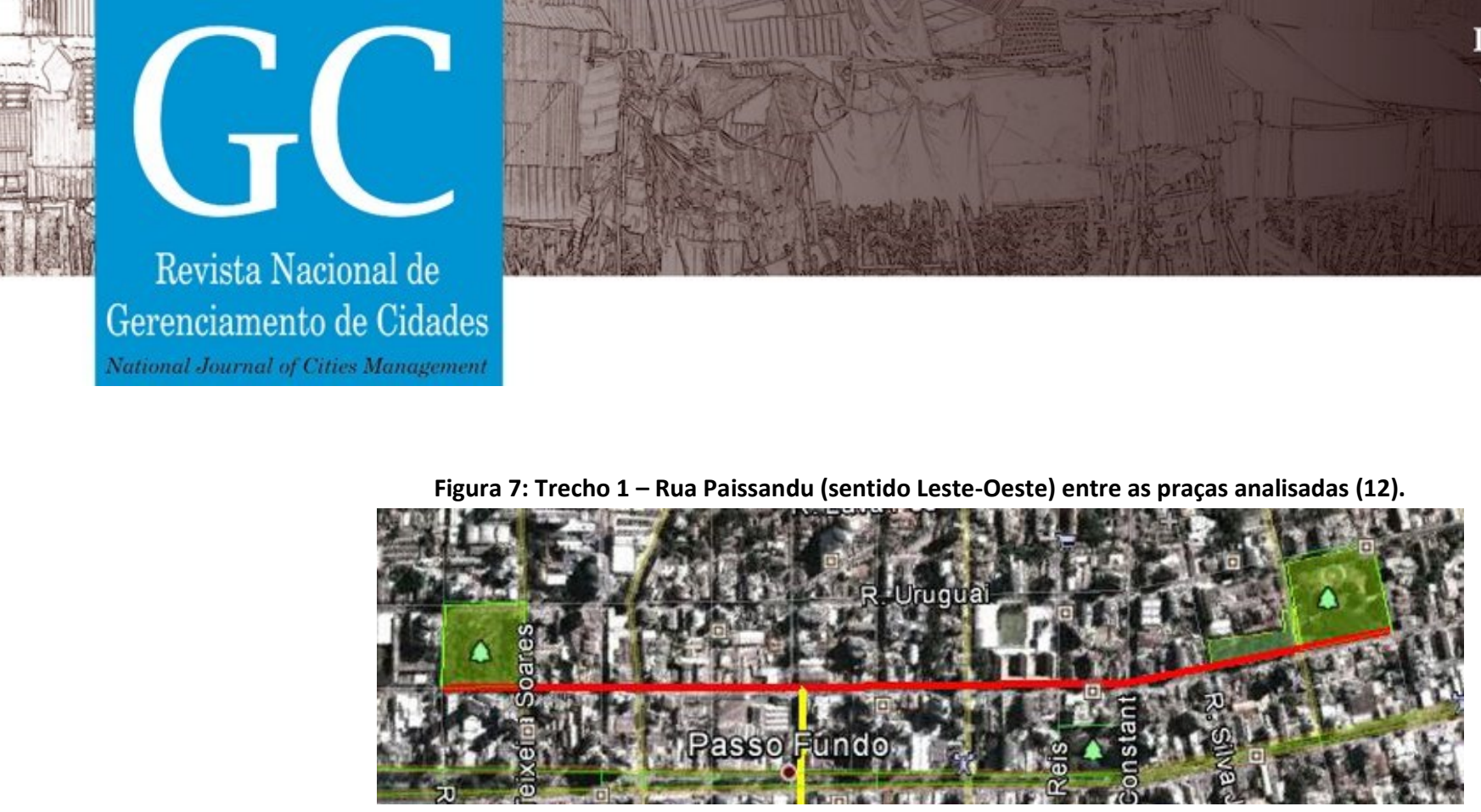

Fonte: Fonte: Adaptação a partir de Google Earth, 2013

Ambas as praças estão localizadas na região central de Passo Fundo. Sua forma quadrada é originária da malha xadrez presente na estruturação urbana de todo o entorno imediato, o que facilita a sua integração na possível rede de infraestrutura verde. A região se destaca pela concentração de serviços médicos; possui também uso comercial e varejista e equipamentos e mobiliários urbanos para o convívio social, encontros e observação da vida pública, como bancos e playgrounds. Figuras 8 e 9. São locais de extrema importância para a cidade. Revelam-se como espaços aconchegantes pela presença da vegetação. Possuem um potencial enorme para se transformar em locais mais atrativos que atendam as possibilidades de formar parte da proposta de infraestrutura verde da cidade.

Observando o uso desses espaços, verifica-se que a praça continua a ser cena metáfora da vida cidadã. Em torno das praças nasceram as cidades. Nelas, os povoadores se transformam em citadinos, reunindo-se para peticionar às autoridades, para protestar, para celebrar ritos cívicos, esportivos, musicais, culturais. Estes espaços continuam a ser também lugares de encontro fortuito, do bate papo informal, da conversa. Mas são outros os protagonistas: o bate papo acontece entre os taxistas que esperam seus clientes à sombra das árvores, os anciãos e seus acompanhantes desfrutam da paisagem, os usuários do transporte público se agrupam nos pontos de ônibus, jovens que praticam esportes, mães que passeiam com seus filhos. A praça continua viva de maneira diferente.

A observação ambiental verifica que, em ambas as praças, a insolação de inverno cria um efeito assimétrico, com espaços diferenciados: leve predominância de áreas sombreadas em relação às ensolaradas, fazendo que as praças sejam mais agradáveis no verão. Criam-se, assim, características distintas no seu comportamento climático. A presença da vegetação permite que as praças sejam habitáveis durante a maior parte do ano já que o período frio é apenas de três meses, cada vez mais curto, talvez devido à mudança climática global.

A iluminação artificial na Praça Tamandaré é antiga, os típicos globos difusores leitosos estão distribuídos uniformemente sem destacar nenhum espaço em especial. Na Praça Antônio Xavier, a iluminação noturna esta composta por luminárias de tipo pétalas localizadas a grande altura, com lâmpadas de vapor de sódio antigas que distorcem as cores da vegetação e dos 


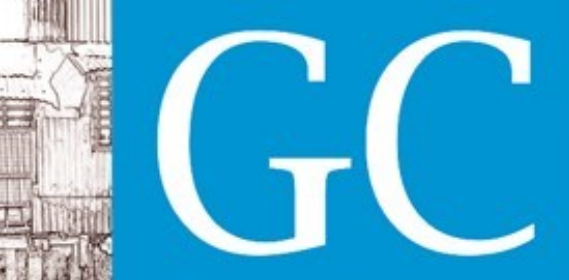

Revista Nacional de

componentes do espaço. No estudo de sua integração na rede de corredores verde, a iluminação artificial oferece uma boa oportunidade de projeto integrado.

Figura 8: Planta, vista e luminária da Praça Tamandaré, Passo Fundo, RS
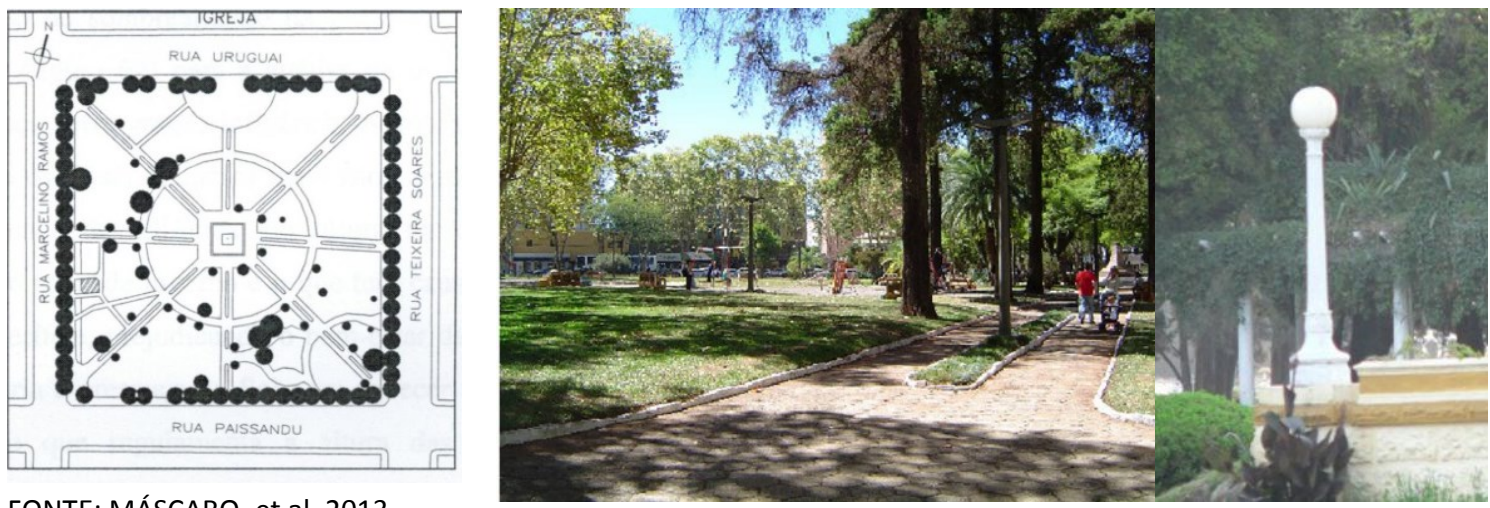

FONTE: MÁSCARO, et al, 2013

Figura 9: Planta, vista e luminária da Praça Antônio Xavier, Passo Fundo, RS
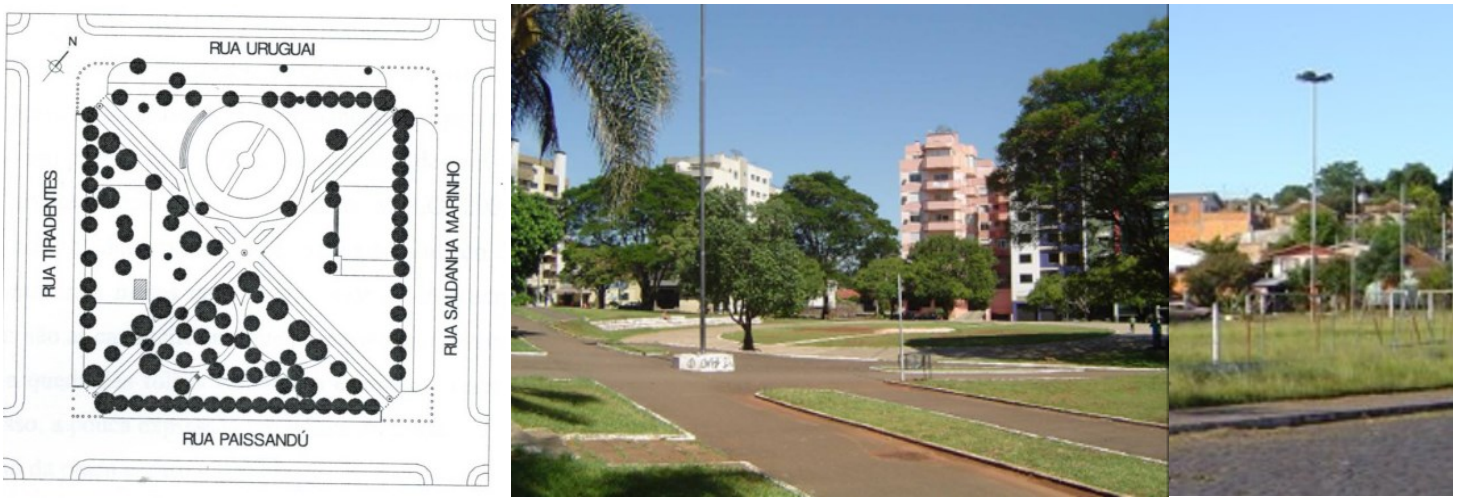

FONTE: MÁSCARO, et al, 2013

Como conclusão do levantamento, pode-se observar alguns aspectos em relação:

\section{- Praças}

Pela localização e características, as praças analisadas definem-se como espaços adequados para formar parte da infraestrutura verde proposta para a cidade. São espaços de qualidade, vitais, com manutenção correta e uso intenso. Espaços que se conformam por várias aberturas no tecido urbano que direcionam naturalmente os mais diversos fluxos em busca dos, também, mais diversos usos, que imprimem a esses espaços o caráter de lugar e ponto central de manifestação da vida pública.

- $\quad$ Sistema viário e drenagem urbana 
A situação ambiental urbana e econômica da maior parte da população urbana de Passo Fundo (e não só a analisada nos trechos escolhidos para o estudo) impõe o uso racional dos poucos percursos disponíveis.

É necessário ressaltar que a pavimentação e a drenagem das águas pluviais significam entre $55 \%$ e $60 \%$ do custo total das redes (água, esgoto, gás, eletricidade, iluminação, pavimentação e drenagem). Portanto, é fundamental para a economia de custos de infraestrutura projetar o espaço de forma a minimizar a área a ser pavimentada a fim de que, em grande parte desse espaço, o pavimento possa ser projetado para um trânsito leve como, por exemplo, nas vias locais de pouco trânsito ou sem saída.

Proposta: Podem-se criar áreas com melhoramentos de baixo custo para recreação, arborização, estacionamento, constituindo espaços públicos de usos múltiplos.

\section{- $\quad$ Calçadas permeáveis}

As superfícies permeáveis são possíveis soluções com forte potencial paisagístico que tornam mais agradáveis ruas, calçadas e estacionamentos agregando valor aos imóveis. Os recintos urbanos com pisos permeáveis e uso intensivo de vegetação podem trazer uma contribuição à sustentabilidade, com ênfase na prevenção das enchentes, redução das ilhas de calor e manutenção das vazões dos cursos de água nas épocas de seca. Recomendamos seu uso discreto fundamental para permitir que, por um lado, sejam atendidas, satisfatoriamente, as exigências de uso (circular); de outro, as de permeabilidade.

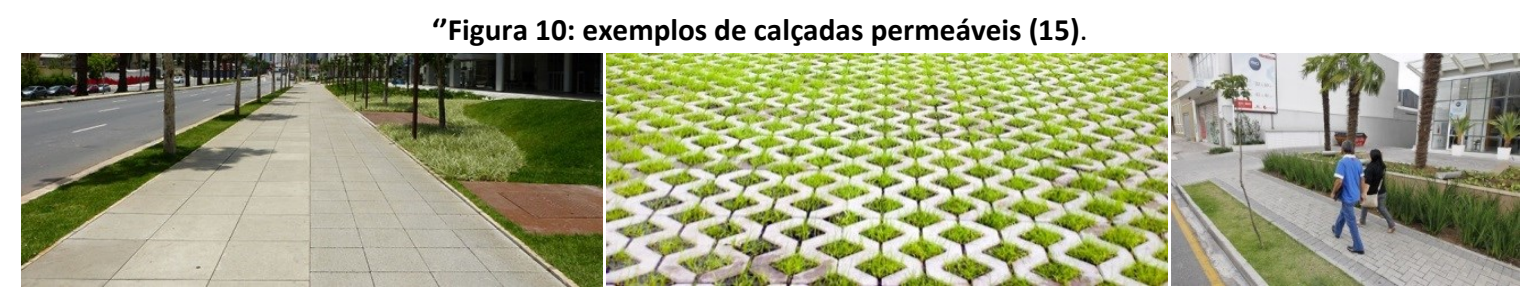

Fonte: http://www.aecweb.com.br/cont/m/rev/pavimentos-permeaveis, 2017

\section{- $\quad$ Pavimentos permeáveis}

Os pavimentos permeáveis (Figura 10) são sistemas de baixo impacto ambiental em que a água permeia através de sua superfície, permitindo a infiltração natural, que é uma forma simples de escoar os poluentes carregados pela chuva. Recomendamos para serem usados em ruas secundárias ou becos sem saída, passeios ou estacionamentos, de forma a se obter uma aparência formal amena. Sua implantação progressiva pode ser uma ação de demonstração adequada para obter o apoio da comunidade nesta ação.

\section{- $\quad$ Arborização}

Priorizar o tema das árvores e os espaços verdes nas agendas e orçamentos das prefeituras municipais depende, em grande parte, de demonstrar que os recursos naturais bem administrados brindam rendimentos econômicos favoráveis para toda a comunidade. Esta perspectiva contrasta com as atitudes do poder público, em que árvores e espaços verdes são 

O sucesso da implantação de infraestrutura verde nas cidades depende tanto do planejamento que envolva ações a médio e longo prazo quanto de ações imediatas, que visem à mitigação dos efeitos negativos já configurados. Neste último caso, é fundamental a consideração das condições existentes, para que as propostas não sejam descoladas da realidade nem inviáveis técnica e economicamente.

Cabe salientar, entretanto, que é necessário fazer o advocacy por cidades saudáveis junto com os governos locais, demonstrando a necessidade e importância de se colocar a infraestrutura verde como elemento fundamental para um planejamento e desenvolvimento urbano mais sustentável.

A conjugação das estratégias sugeridas para os trechos pesquisados permitirá a configuração de um corredor verde conectando as áreas verdes livres, configurando um "embrião" de infraestrutura verde, trazendo melhor impacto visual, climático e de qualidade de vida, inclusive em longo prazo, contribuindo para a sustentabilidade urbana de Passo Fundo.

\section{REFERÊNCIAS BIBLIOGRÁFICAS}

AHERN, J. Greenways in the USA: theory, trends and prospects. In: JONGMAN, R.; PUNGETTI, G. (eds). Ecological Networks and Greenways: Concept, Design, Implementation. Cambridge: University Press, 2003.

BENEDICT, M.A.; McMAHON, E. T. Green Infrastructure for 21st Century. Washington: Sprawl Watch Clearinghouse Monograph Series, The Green Infrastructure, 2004.

COMITÊ ACOMPANHAMENTO OBRAS INFAESTRUTURA VIÁRIA DA REGIÃO METRPOLITANA DE PORTO ALEGRE. Disponível em <http://comiteobrasbr116.blogspot.com.br/2013/10/obras-de-passarela-da-freeway-naregiao.html> Acesso em 10.mar.2017

FRISCHENBRUDER, M. T. M; PELLEGRINO, P. Using greenways to reclaim nature in Brazilian cities, Landscape and Urban Planning, v. 76, n. 1-4, p. 67-78, 2006

GOOGLE EARTH. [Imagens/Mapas]. 2017. Disponível em: <http://www.google.com.br >. Acesso em: 11 mar. 2017

HERZOG, C. P. Corredores verdes: expansão urbana sustentável através da articulação entre espaços livres, conservação ambiental e aspectos histórico-culturais. In: TERRA, C. G. e ANDRADE, R. de. Coleção Paisagens Culturais. Materialização da Paisagem através das Manifestações Sócio-Culturais. Rio de Janeiro: UFRJ - EBA, 2008.

MÁSCARO, Juan José. et al. Infraestrutura verde: base de desenvolvimento sustentável para as cidades de médio porte. Relatório Final de Pesquisa 2013. Passo Fundo, 2013.

OLIVEIRA, L.; MASCARÓ, J. J. Análise da qualidade de vida sob a ótica dos espaços públicos de lazer, Ambiente Construído, Porto Alegre, v.7, n.2, p. 21-31, abril / junho 2007.

RESERVA ECOLÓGICA COSTANEIRA SUR, Buenos Aires, Ar. Disponível em

$<$ http://www.buenosairesturismo.com.br/passeios/reserva-ecologica-costanera-sur.php>. Acesso em 10.mar.2017 
